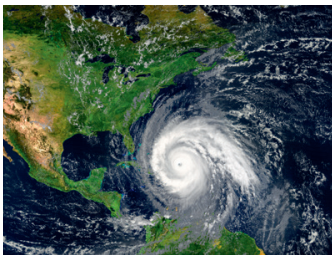

\section{Rebuilding a resilient future for Puerto Rico after Hurricane Maria}

\author{
By Sarah Vorpahl
}

$T^{n}$ he year 2017 produced 17 named hurricanes, six of which were classified as a Category 3 or higher, according to the US National Oceanic and Atmospheric Administration (NOAA). ${ }^{1}$ One of these, Hurricane Maria, brought unprecedented devastation to Puerto Rico on September 20, 2017, with winds over $150 \mathrm{mph}$ and nearly 25 inches of rain. Thousands of Americans died as a result of these storms, and the islands are still trying to recover. One of the biggest impacts came with the destruction of the electric grid, which suffered a complete power outage and took nearly a year to restore. The failure of the electrical system had far-ranging effects on health, education, jobs, agriculture, and safety.

Even before the storm, Puerto Rico was paying some of the highest energy rates in the United States, with most of the electricity on the island coming from expensive imported fossil fuels, such as diesel and coal. Despite abundant solar resources on the island, the renewable energy penetration was less than $2 \%$, falling short of the Renewable Portfolio Standard goal of $12 \%$ by 2015 .
As is evident from the degree of power outages (and ongoing issues), a centralized electrical grid that has existed in Puerto Rico is vulnerable to hurricanes, which are predicted to increase in severity in the future because of climate change. Despite the fact that many are pushing for a return to a fossil fuel infrastructure, local community efforts across Puerto Rico have begun to create their own renewable energy sources. For example, Casa Pueblo, a self-reliant communitybased organization located in Adjuntas, has continued to install solar systems after its own operations remained intact, and provided support for the local community after the storm.

Scientists have also been stepping in to bring solar to the island. Lilo Pozzo, a professor of chemical engineering at the University of Washington, brought a team of graduate students from the Clean Energy Institute to a remote mountain community called Jayuya to install 21 solar plus storage nanogrid systems. ${ }^{2}$ This type of microgrid technology could lead to sustainable, clean energy infrastructures that can back up public health infrastructures and other needs when the lights go out. (See the article "Rebuilding better electrical grids in disaster zones," by Scott Litzelman in the November 2018 issue of MRS Bulletin.)

Immediately following the storm, a US working group, which included several national laboratories, power authorities, the State of New York, and others, developed a roadmap ${ }^{3}$ for the resilient rebuilding of Puerto Rico's grid. This document collected and analyzed Puerto Rico's power system information, both before and after the storm, and made recommendations that included making smart grid investments to bring more distributed resources online, rebuilding with renewable energy, and automating control systems. The US Department of Energy (DOE) also compiled a plan ${ }^{4}$ for a roadmap for grid modernization in Puerto Rico, and urged detailed modeling of the electrical system to optimize use of microgrids and co-locating power generation to lower the burden on the transmission system (especially given the cost of rerouting current transmission lines). A summary of the plans related to modernizing Puerto Rico's grid can be found in the appendix of the DOE report.
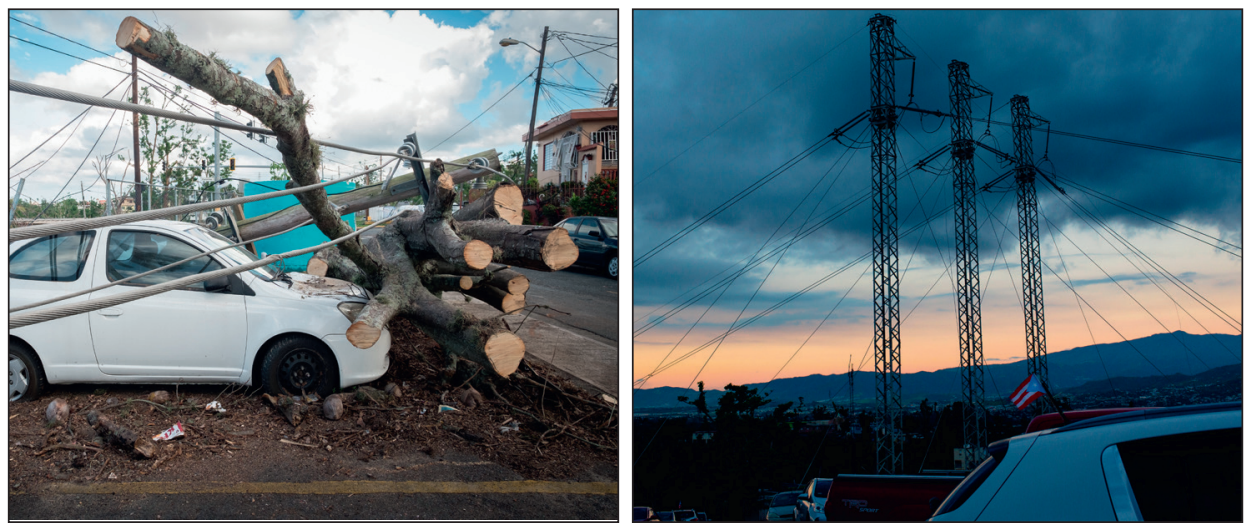

Recently, legislation supported by the mayors and many groups in Puerto Rico proposed a mandate that would require $50 \%$ renewable electricity by 2035 and $100 \%$ by 2050 , following a report ${ }^{5}$ by the Institute for Energy Economics and Financial Analysis. The plan, called "Queremos Sol" (We Want Sun), outlines an aggressive strategy that mirrors a similar recently enacted mandate in California, SB 100. The mandate would be reached through several strategies: efficiency,
The devastating aftermath in Puerto Rico almost three months after Hurricane Maria. Left: the power grid in Caimito broken and in disarray alongside roads and houses, endangering residents. Right: Damaged power lines in the Mariana community of Humacao. Photo credit: Shutterstock. 
conservation and demand management, distributed renewable generation with storage, an emphasis on rooftop solar, and accelerated elimination of fossil fuels.

In addition to the technical work of restoring the grid in Puerto Rico, some US Congress members have worked to address the deeper needs of a resilient rebuild. The post-hurricane power problems in Puerto Rico were catalyzed by many factors, including an aging electrical grid, but also historic territorial status, which under-
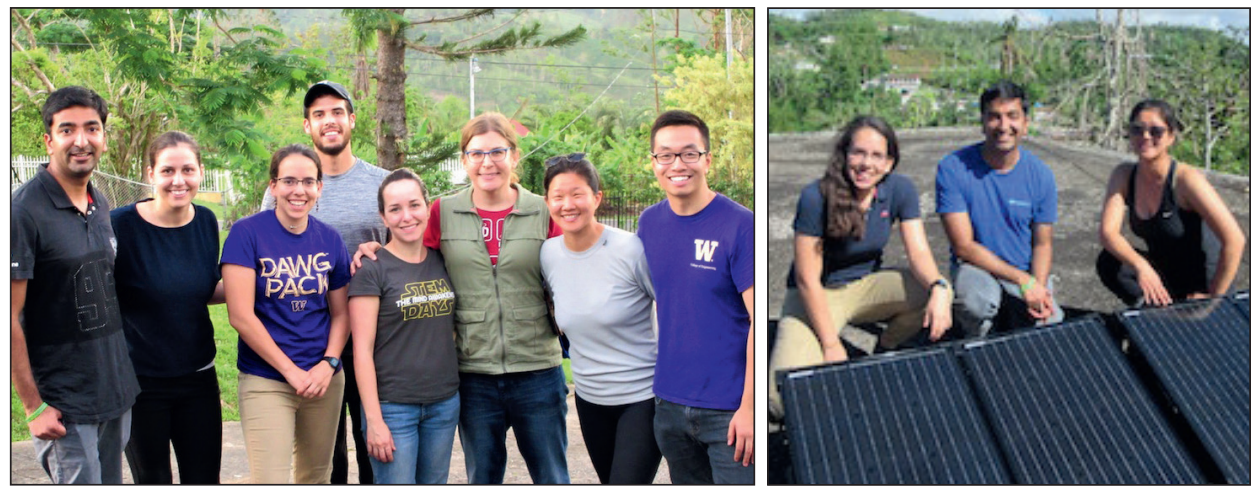

University of Washington graduate students assist in research and recovery efforts in Jayuya, Puerto Rico, after Hurricane Maria. Left: Chanaka Keerthisinghe, Erin Palmisano, Mareldi Ahumada, Wes Tatum, Marvi Matos, professor Lilo Pozzo, Lauren Kang, and Chester Pham. Right: Ahumada, Keerthisinghe, and Kang with recently installed solar cells on the roof of the community center. Photo credit: Clean Energy Institute, University of Washington, www.cei.washington.edu. funded many programs, and a massive debt (USD\$74 billion in bond debt and USD\$49 billion in unfunded pension liabilities). Before the storm, the poverty rate in Puerto Rico (at $46 \%$ ) was double the average of the mainland states, and unemployment was twice the national average. A year after the storms, the impact of these dynamics is only now being fully understood.

US Senator Bernie Sanders took the lead in the Senate to create a sweeping piece of legislation that not only brought emergency relief to both Puerto Rico and the US Virgin Islands, but also attempted to ameliorate the historic backlog of funding for services to the territories. The Puerto Rico and Virgin Islands Equitable Rebuild
Act of 2017, co-sponsored by seven Democrats in the Senate and endorsed by 75 organizations, touched on agriculture, health care, education, worker's rights, and the electrical grid. The comprehensive legislation has been referred to as the "Marshall Plan" for the territories.

"It is unconscionable that in the wealthiest nation in the world, we have allowed our fellow citizens to suffer for so long. The full resources of the United States must be brought to bear on this crisis, for as long as is necessary," said Sanders in a press release ${ }^{6}$ about the bill. "But we cannot simply rebuild Puerto Rico and the US Virgin Islands the way they were. We must go forward to create a strong, sustainable

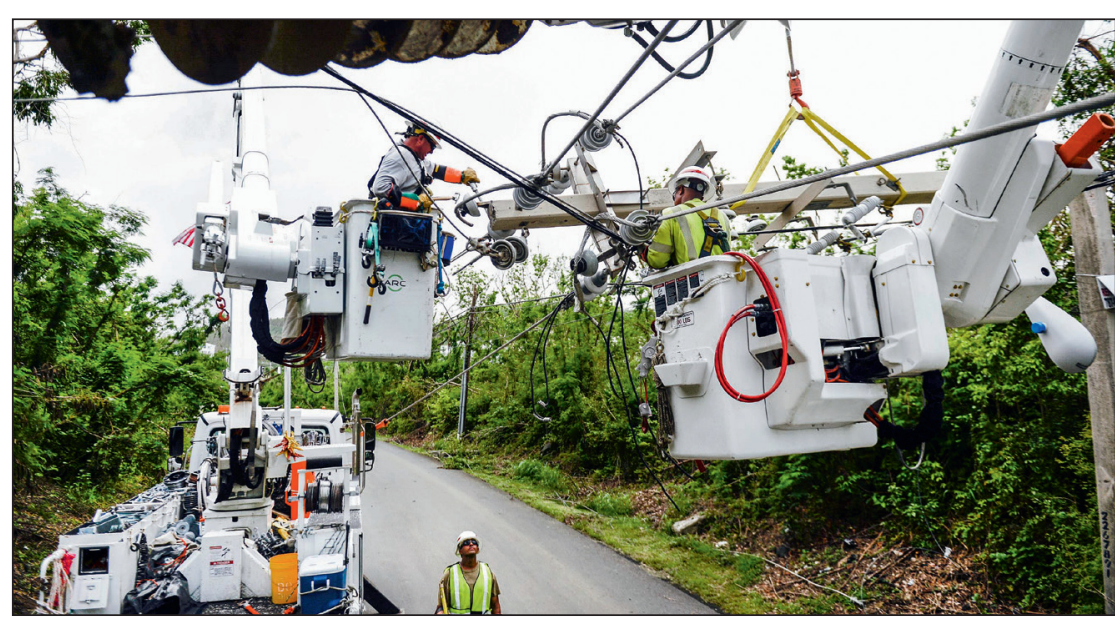

Transmission and distribution specialists assigned to Company D, 249th Engineer Battalion (Prime Power) of the US Army Corps of Engineers, repair power lines in Rio Grande, Puerto Rico, after Hurricane Maria. Photo credit: Master Sgt. Joshua L. DeMotts, US Department of Defense. economy and energy system in both territories and address inequities in federal law that have allowed the territories to fall behind in almost every measurable social and economic criteria," said Sanders.

The rebuilding in Puerto Rico continues, as the worst effects of climate change are only beginning. A resilient Puerto Rico means not only clean, self-reliant energy, but also robust social programs that ensure communities have access to the same resources as the other 50 US states.

\section{References}

1. NOAA, "Extremely Active 2017 Atlantic Hurricane Season Finally Ends," www.noaa.gov/media-release/extremelyactive-2017-atlantic-hurricane-season-finally-ends. Media release, November 30, 2017.

2. C. Keerthisinghe, M. Ahumada-Paras, L.D. Pozzo, D.S. Kirschen, H. Pontes, W.K Tatum, M.A. Matos, "PV-Battery Systems for Critical Loads During Emergencies: A Case Study from Puerto Rico after Hurricane Maria," IEEE Power \& Energy Magazine 17 (6) (January-February 2019).

3. Puerto Rico Energy Resiliency Working Group, Build Back Better: Reimagining and Strengthening the Power Grid of Puerto Rico (December 2017), www.governor.ny.gov/sites/ governor.ny.gov/files/atoms/itles/PRERWG_Report_PR_ Grid_Resiliency_Report.pdf.

4. US Department of Energy, Energy Resilience Solutions for the Puerto Rico Grid (June 2018), www.energy.gov/sites/ prod/files/2018/06/f53/DOE\%20Report_Energy\%20 Resilience\%20Solutions\%20for\%20the\%20PR\%20 Grid\%20Final\%20June\%202018.pdf.

5. Institute for Energy Economics and Financial Analysis, We Want Sun (October 2018), http://ieefa.org/wp-content/ uploads/2018/10/We-Want-Sun-ENG-10_03_18.pdf.

6. B. Sanders, "Sanders Colleagues Unveil Legislation to Rebuild Puerto Rico and Virgin Islands," www.sanders. senate.gov/newsroom/press-releases/sanders-colleaguesunveil-legislation-to-rebuild-puerto-rico-and-virginislands. Press release, November 28, 2017. 


\section{The Materials Research Society and \\ Cambridge University Press}

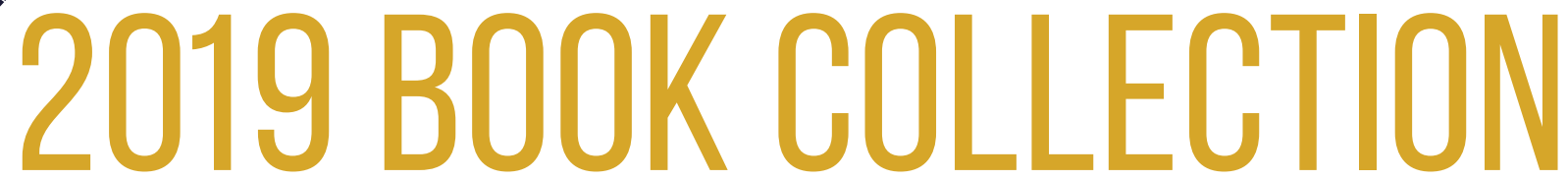

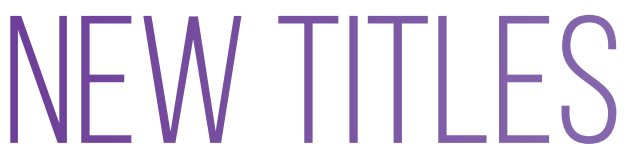
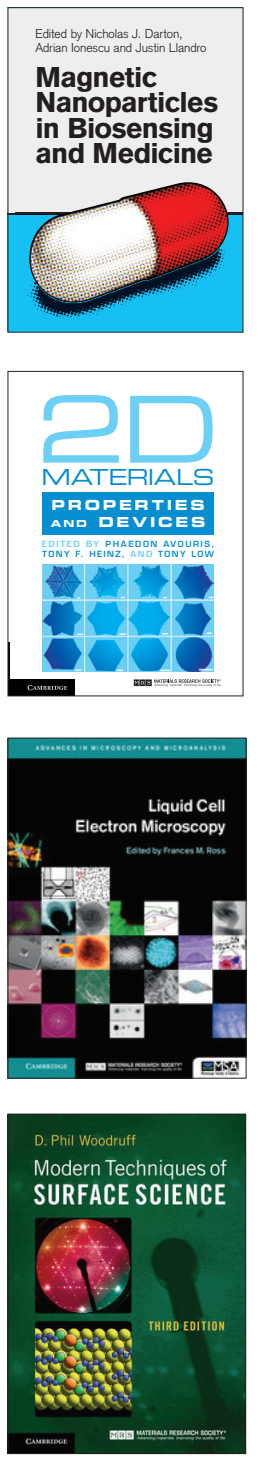

Modern Techniques of Surface Science Third Edition

AUTHOR: D. Phil Woodruff

ISBN: 9781107023109

List Price: $\$ 110.00$

MRS Member Price: $\$ 88.00$

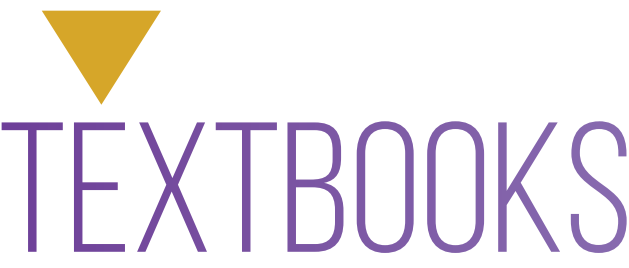

MATERIALS

ENGINEERING
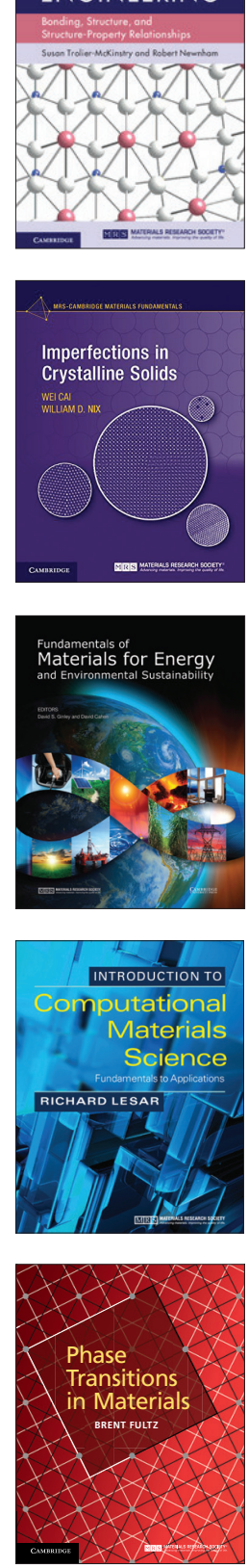

NEW TEXTBOOK

Materials Engineering-

Bonding, Structure, and Structure-Property

Relationships

AUTHORS: Susan Trolier-McKinstry and Robert E. Newnham ISBN: 9781107103788

List Price: $\$ 95.00$

MRS Member Price: $\$ 76.00$

Imperfections in Crystalline Solids

First Textbook in the New MRS-Cambridge Materials Fundamentals Series

AUTHORS: Wei Cai and William D. Nix

ISBN: 9781107123137

List Price: $\$ 65.00$

MRS Member Price: $\$ 52.00$

Fundamentals of Materials for Energy and Environmental Sustainability

EDITORS: David S. Ginley

and David Cahen

ISBN: 9781107000230

List Price: $\$ 119.00$

MRS Member Price: $\$ 95.00$

Introduction to Computational Materials Science

Fundamentals to Applications

AUTHOR: Richard LeSar

ISBN: 9780521845878

List Price: $\$ 95.00$

MRS Member Price: $\$ 76.00$

Phase Transitions in Materials

AUTHOR: Brent Fultz

ISBN: 9781107067240

List Price: $\$ 113.00$

MRS Member Price: $\$ 90.00$

To view the entire collection, visit www.cambridge.org/mrs-cambridge 